\title{
Quantitative SARS-CoV-2 Antibody Screening of Healthcare Workers in the Southern Part of Kyoto City During the COVID-19 Pre-pandemic Period
}

\section{OPEN ACCESS}

Edited by:

Thomas Rawson,

University of Oxford, United Kingdom

Reviewed by:

Pedro Xavier-Elsas,

Federal University of Rio de

Janeiro, Brazil

Masaki Fujita,

Fukuoka University, Japan

*Correspondence:

Kohei Fujita

kfujita-oka@umin.ac.jp

tThese authors have contributed equally to this work

Specialty section: This article was submitted to Infectious Diseases - Surveillance,

Prevention and Treatment,

a section of the journal

Frontiers in Public Health

Received: 16 August 2020 Accepted: 17 November 2020 Published: 07 December 2020

Citation:

Fujita K, Kada S, Kanai O, Hata H,

Odagaki T, Satoh-Asahara N,

Tagami T and Yasoda A (2020) Quantitative SARS-CoV-2 Antibody Screening of Healthcare Workers in the Southern Part of Kyoto City During the COVID-19 Pre-pandemic Period.

Front. Public Health 8:595348. doi: 10.3389/fpubh.2020.595348

\begin{abstract}
Kohei Fujita ${ }^{1,2 * t}$, Shinpei Kada ${ }^{2,3+}$, Osamu Kanai ${ }^{1,2}$, Hiroaki Hata ${ }^{2,4}$, Takao Odagaki ${ }^{2,5}$, Noriko Satoh-Asahara ${ }^{6,7}$, Tetsuya Tagami ${ }^{6,7}$ and Akihiro Yasoda ${ }^{6,7}$

${ }^{1}$ Division of Respiratory Medicine, Center for Respiratory Diseases, National Hospital Organization Kyoto Medical Center, Kyoto, Japan, ${ }^{2}$ Department of Infectious Diseases, National Hospital Organization Kyoto Medical Center, Kyoto, Japan, ${ }^{3}$ Department of Otolaryngology, Head and Neck Surgery, National Hospital Organization Kyoto Medical Center, Kyoto, Japan, ${ }^{4}$ Department of Surgery, National Hospital Organization Kyoto Medical Center, Kyoto, Japan, ${ }^{5}$ Department of General Medicine, National Hospital Organization Kyoto Medical Center, Kyoto, Japan, ${ }^{6}$ Department of Endocrinology and Metabolism, National Hospital Organization Kyoto Medical Center, Kyoto, Japan, ${ }^{7}$ Division of Endocrinology, Metabolism, and Hypertension Research, Clinical Research Institute, National Hospital Organization Kyoto Medical Center, Kyoto, Japan
\end{abstract}

Background: The coronavirus disease-2019 (COVID-19) pandemic is associated with a heavy burden on the mental and physical health of patients, regional healthcare resources, and global economic activity. While understanding of the incidence and case-fatality rates has increased, there are limited data concerning seroprevalence of antibodies against the severe acute respiratory syndrome-coronavirus-2 (SARS-CoV-2) in healthcare workers during the pre-pandemic period. This study aimed to quantitatively evaluate seroprevalence of SARS-CoV-2 antibodies in healthcare workers in the southern part of Kyoto city, Japan.

Methods: We prospectively recruited healthcare workers from a single hospital between April 10 and April 20, 2020. We collected serum samples from these participants and quantitatively evaluated SARS-CoV-2 IgG antibody levels using enzyme-linked immunosorbent assays.

Results: Five (5.4\%), 15 (16.3\%), and 72 (78.3\%) participants showed positive, borderline, and negative serum SARS-CoV-2 lgG antibody status, respectively. We found the mean titer associated with each antibody status (overall, positive, borderline, and negative) was clearly differentiated. Participants working at the otolaryngology department and/or with a history of seasonal common cold symptoms had a significantly higher SARS-CoV-2 IgG antibody titer ( $p=0.046, p=0.046$, respectively).

Conclusions: Five (5.4\%) and 15 (16.3\%) participants tested positive and borderline, respectively, for SARS-CoV-2 IgG antibody during the COVID-19 pre-pandemic period. These rates were higher than expected, based on government situation reports. These findings suggest that COVID-19 had already spread within the southern part of Kyoto city at the early stage of the pandemic.

Keywords: COVID-19, seroprevalence, SARS-CoV-2, ELISA, antibody 


\section{INTRODUCTION}

Coronavirus disease-2019 (COVID-19) is caused by the severe acute respiratory syndrome coronavirus-2 (SARS-CoV-2). COVID-19 was first reported in Wuhan, China, in December 2019, and the outbreak was subsequently declared a pandemic by the World Health Organization (WHO) on March 11, 2020 (1). The disease course varies from mild and self-limiting upper respiratory infection symptoms to severe respiratory failure, which might require respiratory support $(2,3)$. By mid-March 2020, pandemic centers were located in China, the United States, and several European countries. In Japan, the government announced a state of emergency on April 4, 2020. At the end of July 2020, >750,000 people worldwide had died of COVID-19 $(1,4)$. COVID-19 is associated with a heavy burden on the mental and physical health of patients, regional healthcare resources, and global economic activity. Effective policies to deal with the pandemic are required and should be founded on reliable epidemiological data. The diagnosis of COVID-19 is based on viral nucleic acid detection using a reverse-transcription polymerase chain reaction (RT-PCR) assay for SARS-CoV-2. Whereas, an RT-PCR assay is accurate at detecting an active case of COVID-19, identifying individuals who have recovered from SARS-CoV-2 infection has been challenging. In contrast to tracking active cases, antibody detection can provide information on individual and herd-acquired immunity against SARS-CoV-2. Furthermore, an antibody assay can help to estimate the number of people within a community who remain potential cases, assisting governments in effective decision-making. To date, data concerning the seroprevalence of SARS-CoV-2 antibodies in healthcare workers worldwide are limited. During the prepandemic period, we quantitatively evaluated the seroprevalence of SARS-CoV-2 antibodies in healthcare workers in the southern part of Kyoto city, an area famous for its heritage status and a popular tourist destination.

\section{PARTICIPANTS AND METHODS}

\section{Participants}

This study was conducted at the National Hospital Organization Kyoto Medical Center (600 beds), located in southern Kyoto, Japan. In response to the pandemic, our hospital formed an infectious disease department dedicated to COVID-19, involving medical staff such as internal medicine physicians, chest physicians, general and thoracic surgeons, cardiologists, nephrologists, otolaryngologists, and emergency physicians. We prospectively recruited medical doctors, nurses, and ward clerks employed at our hospital between April 10 and April 20, 2020. All participants were asymptomatic and worked within any of the following departments: infectious disease, respiratory medicine, otolaryngology, or emergency medicine. Healthcare workers from these departments were selected as they were considered more likely to treat patients with suspected COVID19, of which they might not have been aware. Additionally, we collected the following questionnaire-based data: a history of seasonal common cold from winter 2019 to early spring 2020 and a history of regular contact with children aged $<12$ years. The questionnaires were created based on previous studies involving behavior patterns during the H10N8 avian influenza outbreak (5).

\section{ELISA Assay}

We collected $6 \mathrm{ml}$ of blood from each participant between April 10 and April 20, 2020. After extracting serum, we deep froze and stored the samples at $-80^{\circ} \mathrm{C}$. We used an enzymelinked immunosorbent (ELISA) assay, using COVID-19 IgG ELISA kits (DRG international, Inc. Springfield, NJ, USA), to evaluate the presence of serum IgG antibody against SARS-CoV2 , in accordance with the manufacturer's instructions. Briefly, 1:100 diluted human serum samples were placed onto a 96well microplate (coated with SARS-CoV-2 recombinant fulllength nucleocapsid protein) and then incubated for $30 \mathrm{~min}$ at room temperature $\left(20-25^{\circ} \mathrm{C}\right)$. After washing, $100 \mu \mathrm{l} \mathrm{HRP-}$ labeled anti-IgG tracer antibody was added into the wells and the samples were incubated for $30 \mathrm{~min}$ at room temperature $\left(20-25^{\circ} \mathrm{C}\right)$. Following the second wash cycle, $100 \mu \mathrm{l}$ substrate was added into the wells and the samples were incubated for $20 \mathrm{~min}$ at room temperature $\left(20-25^{\circ} \mathrm{C}\right)$. Last, stop solution was added into the wells to terminate the reaction. The optical density of each well was determined using a microplate reader set to $450 \mathrm{~nm}$ within $10 \mathrm{~min}$. For IgG detection, the cut-off value was modified through using an internal negative and positive control of Japanese samples, because of the differences in ethnicity between ELISA kits (Chinese controls) and our samples (Japanese). We interpreted the results as positive, borderline, and negative, according to the manufacturer's instructions.

\section{Statistical Analysis}

The data were analyzed using JMP version 14.0.0 (SAS institute Inc. Cary, NC). A Fisher's exact test was used to compare proportions among occupations, wards, questionnaires, and SARS-CoV-2 IgG antibody status. Wilcoxon rank sum or Kruskal-Wallis tests, as appropriate, were used to compare SARSCoV-2 IgG antibody titers between groups, and $p$-values $<0.05$ were considered statistically significant.

\section{Ethical Approval}

This study was approved by the relevant institutional review boards (approval number: 20-009) and written informed consent was obtained from all study participants.

\section{RESULTS}

In total, 92 healthcare workers were recruited for this study. Medical doctors, nurses, and medical clerks comprised 42 (45.7\%), $48(52.2 \%)$, and $2(2.2 \%)$ participants, respectively. Of 92 participants, 59 (64.1\%) were women, and most participants were aged between 20 and 39 years. Among the participants, the otolaryngology department was the most common place of work, followed by the respiratory and emergency medicine departments. Of 92 participants, $47(51.1 \%)$ had a history of seasonal common cold symptoms from winter 2019 to early spring 2020, and 19 (20.7\%) participants had a history of regular contact with children aged $<12$ years (Table 1 ). 
TABLE 1 | Clinical and demographic characteristics of participating healthcare workers.

\begin{tabular}{|c|c|}
\hline & $n=92$ \\
\hline Sex (female) & $59(64.1)$ \\
\hline \multicolumn{2}{|l|}{ Age group (years) } \\
\hline $20-29$ & $30(32.6)$ \\
\hline 30-39 & $29(31.5)$ \\
\hline $40-49$ & $21(22.8)$ \\
\hline$\geq 50$ & $12(13.0)$ \\
\hline \multicolumn{2}{|l|}{ Occupation } \\
\hline Medical doctor & $42(45.7)$ \\
\hline Nurses & $48(52.2)$ \\
\hline Medical clerk & $2(2.2)$ \\
\hline \multicolumn{2}{|l|}{ Department } \\
\hline Department of Infectious Diseases & $18(19.6)$ \\
\hline Respiratory Medicine Ward & $22(23.9)$ \\
\hline Otolaryngology Ward & $30(32.6)$ \\
\hline Emergency Medicine Ward & $22(23.9)$ \\
\hline \multicolumn{2}{|l|}{ Questionnaire } \\
\hline *History of seasonal common cold symptoms & $47(51.1)$ \\
\hline${ }^{*}$ History of regular contact with children & $19(20.7)$ \\
\hline${ }^{* \star}$ History of exposure to a viral infection & $84(91.3)$ \\
\hline \multicolumn{2}{|l|}{ SARS-CoV-2 antibody status } \\
\hline Positive & $5(5.4)$ \\
\hline Borderline & $15(16.3)$ \\
\hline Negative & $72(78.3)$ \\
\hline $\begin{array}{l}\text { Data are shown as counts (\%). SARS-CoV-2, severe acute } \\
\text { syndrome coronavirus-2. } \\
{ }^{*} \text { Covered period from winter } 2019 \text { to early spring } 2020 \text {, including history of res } \\
\text { with children aged }<12 \text { years. } \\
{ }^{*} \text { Participants considered exposed to viral infection were defined as those w } \\
\text { history of seasonal common cold symptoms and/or examining outpatients w } \\
\text { cold symptoms. }\end{array}$ & $\begin{array}{l}\text { respiratory } \\
\text { ular contact } \\
\text { th their own } \\
\text { ith common }\end{array}$ \\
\hline
\end{tabular}

\section{Seroprevalence of Antibodies Against SARS-CoV-2}

In total, 92 serum samples collected between April 10 and April 20, 2020 were tested for antibodies against SARS-CoV-2. Of 92 participants, $5(5.4 \%), 15(16.3 \%)$, and $72(78.3 \%)$ showed positive, borderline, and negative SARS-CoV-2 IgG antibody test results, respectively (Table $\mathbf{1}$ ). There were no significant differences in antibody status between the professional groups (Table 2). We identified 2 and 3 participants with a positive antibody status in the respiratory disease and otolaryngology departments, respectively. The highest proportion of participants with a positive and borderline SARS-CoV-2 IgG antibody status worked at the otolaryngology department, whereas the lowest proportion were working at the emergency medicine department (Table 3).

Participants with a history of seasonal common cold from winter 2019 to early spring 2020 showed a higher rate of positive SARS-CoV-2 IgG antibody test results than participants with no such history $(p=0.046)$. A history of regular contact with children or of exposure to a viral infection did not affect the seroprevalence of SARS-CoV-2 IgG antibody (Table 4).
TABLE 2 | SARS-CoV-2 IgG antibody seroprevalence among healthcare workers according to occupation.

\begin{tabular}{lllllllll}
\hline & & \multicolumn{4}{c}{ IgG against SARS-CoV-2 } & \multirow{2}{*}{$\boldsymbol{p}$-value } \\
\cline { 5 - 7 } Occupation & $\boldsymbol{n}$ & & Positive & Borderline & Negative & \\
\hline Medical doctor & 42 & 2 & $(4.7 \%)$ & 6 & $(14.0 \%)$ & 34 & $(76.2 \%)$ & 0.9236 \\
Nurse and Medical clerk & 50 & 3 & $(6.0 \%)$ & 9 & $(18.0 \%)$ & 38 & $(76.0 \%)$ & \\
\hline
\end{tabular}

Data are shown as counts (\%). The $p$-value was estimated using the Fisher's exact test, with $p<0.05$ considered statistically significant.

SARS-CoV-2, severe acute respiratory syndrome coronavirus-2.

TABLE 3 | SARS-CoV-2 lgG antibody seroprevalence among healthcare workers according to department.

\begin{tabular}{|c|c|c|c|c|c|c|}
\hline & \multirow[b]{2}{*}{$n$} & \multicolumn{4}{|c|}{ IgG against SARS-CoV-2 } & \multirow[t]{2}{*}{$p$-value } \\
\hline & & Positive & & orderline & Negative & \\
\hline Department of Infectious & 18 & $0 \quad(0.0 \%)$ & 3 & $(16.7 \%)$ & 15 (83.3\%) & 0.2102 \\
\hline \multicolumn{7}{|l|}{ Diseases } \\
\hline Respiratory Diseases Ward & 22 & $2 \quad(9.1 \%)$ & 4 & $(18.2 \%)$ & $16(72.7 \%)$ & \\
\hline Otolaryngology Ward & 30 & $3(10.0 \%)$ & 7 & (23.3\%) & $20(66.7 \%)$ & \\
\hline Emergency Medicine Ward & 22 & $0 \quad(0.0 \%)$ & 1 & $(4.6 \%)$ & 21 (95.5\%) & \\
\hline
\end{tabular}

Data are shown as counts (\%). The $p$-value was estimated using a Fisher's exact test, with $p<0.05$ considered statistically significant.

SARS-CoV-2, severe acute respiratory syndrome coronavirus-2.

TABLE 4 | Seroprevalence of SARS-CoV-2 IgG antibody according to exposure status as determined using a questionnaire.

\begin{tabular}{|c|c|c|c|c|c|c|}
\hline & \multirow[b]{2}{*}{$n$} & \multicolumn{4}{|c|}{ IgG against SARS-CoV-2 } & \multirow[t]{2}{*}{$p$-value } \\
\hline & & Positive & & orderline & Negative & \\
\hline $\begin{array}{l}\text { *History of seasonal } \\
\text { common cold symptoms }\end{array}$ & 47 & $5(10.6 \%)$ & 9 & $(19.2 \%)$ & $33(70.2 \%)$ & 0.0458 \\
\hline $\begin{array}{l}\text { *History of regular contact } \\
\text { with children }\end{array}$ & 19 & $1 \quad(5.3 \%)$ & 1 & $(5.3 \%)$ & 17 (89.5\%) & 0.3294 \\
\hline $\begin{array}{l}{ }^{* \star} \text { History of exposure to a } \\
\text { viral infection }\end{array}$ & 84 & $5 \quad(6.0 \%)$ & 14 & $(16.7 \%)$ & 65 (77.4\%) & $>0.99$ \\
\hline
\end{tabular}

Data are shown as counts (\%). The $p$-value was estimated using a Fisher's exact test, with $p<0.05$ considered statistically significant.

SARS-CoV-2, severe acute respiratory syndrome coronavirus-2.

${ }^{*}$ Covered period from winter 2019 to early spring 2020, including history of regular contact with children aged $<12$ years.

${ }^{*}$ Participants considered exposed to viral infection were defined as those with own history of seasonal common cold symptoms and/or examining outpatients with common cold symptoms.

\section{Serum SARS-CoV-2 IgG Antibody Titer}

The mean antibody titer of all participants was $0.120 \pm 0.0372$ (Figure 1A). The mean titer of the antibody positive, borderline, and negative groups was $0.219 \pm 0.051,0.161 \pm 0.0101$, and $0.105 \pm 0.018$, respectively (Figure 1B). Mean antibody titers stratified according to occupation and department are shown in Figures 2A,B. There were no significant differences in mean antibody titers between doctors, nurses, and medical clerks ( 0.119 \pm 0.0326 and $0.121 \pm 0.0058, p=0.994$; Figure 2A). The mean 


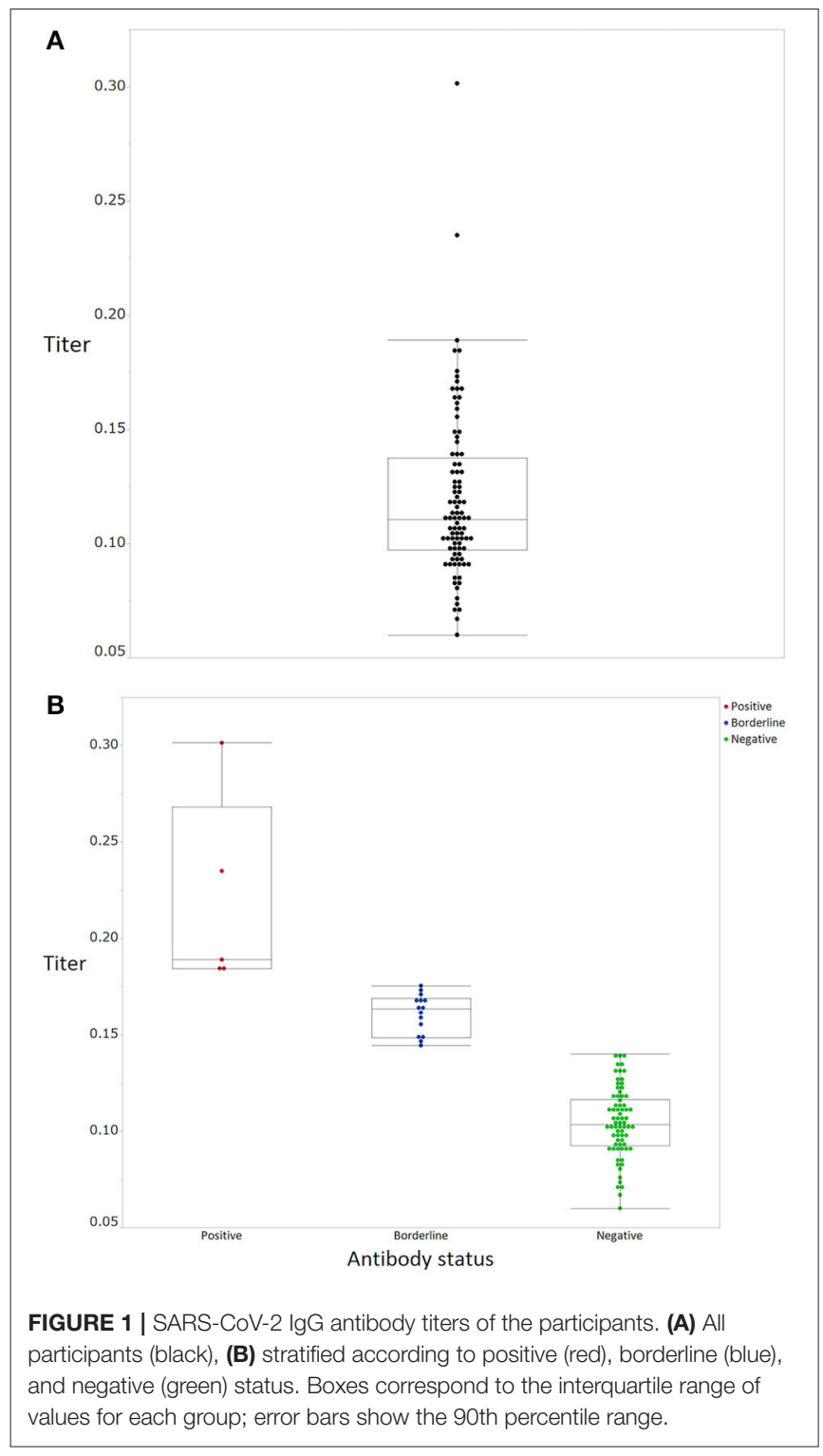

antibody titer among workers at the otolaryngology department was significantly higher than that among workers in the other three departments $(0.112 \pm 0.029,0.121 \pm 0.043,0.134 \pm 0.043$, and $0.11 \pm 0.018, p=0.046$; Figure 2B). Participants with a history of seasonal common cold symptoms had a significantly higher titer of SARS-CoV-2 IgG antibody than those with no such history $(0.13 \pm 0.044$ and $0.11 \pm 0.026, p=0.046$; Figure 3A). There were no significant differences in the mean antibody titer between participants with and without a history of regular contact with children or with a history of exposure to a viral infection ( $p=0.304$, Figure 3B; $p=0.418$, Figure $3 C)$.

\section{DISCUSSION}

In this study, 5 (5.4\%) and 15 (16.3\%) healthcare workers were positive and borderline, respectively, for the presence of SARSCoV-2 IgG antibodies. The mean antibody titer among the
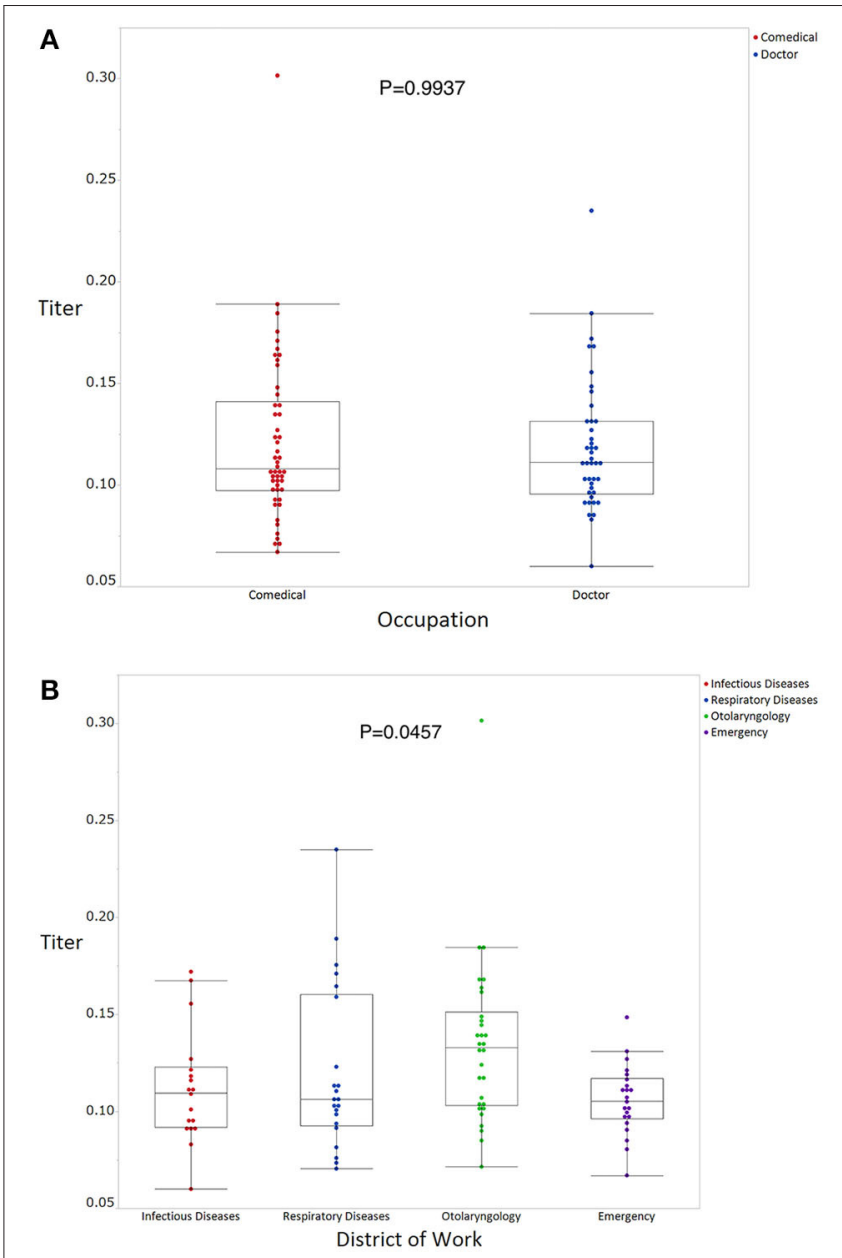

FIGURE 2 | SARS-CoV-2 IgG antibody titers stratified according to occupation (A) and department (B). A Wilcoxon rank sum test (A) or a Kruskal-Wallis test (B) was used to compare the titer of SARS-CoV-2 IgG antibody levels between the groups, with $p$-values $<0.05$ considered statistically significant.

borderline group was clearly distinct from that of the negative group. Participants with borderline antibody results might have been latently sensitized by patients with COVID-19. As our hospital accepted patients with confirmed COVID-19 after April 15,2020 , the antibody status of our study participants might reflect community-acquired immunity, resulting from unwitting exposure in daily medical practice.

The mean antibody titer was significantly higher among workers at the otolaryngology department than among those working in other departments. This suggests that healthcare workers within the otolaryngology department were more likely to be exposed to SARS-CoV-2 than their counterparts working in other departments.

According to official statements from Kyoto city authorities, confirmed incidence and fatality associated with COVID-19 in Kyoto city at the end of April 2020 comprised 215 and 11 cases, respectively (6). However, antibody seroprevalence observed in this study was much higher than that expected, based on 

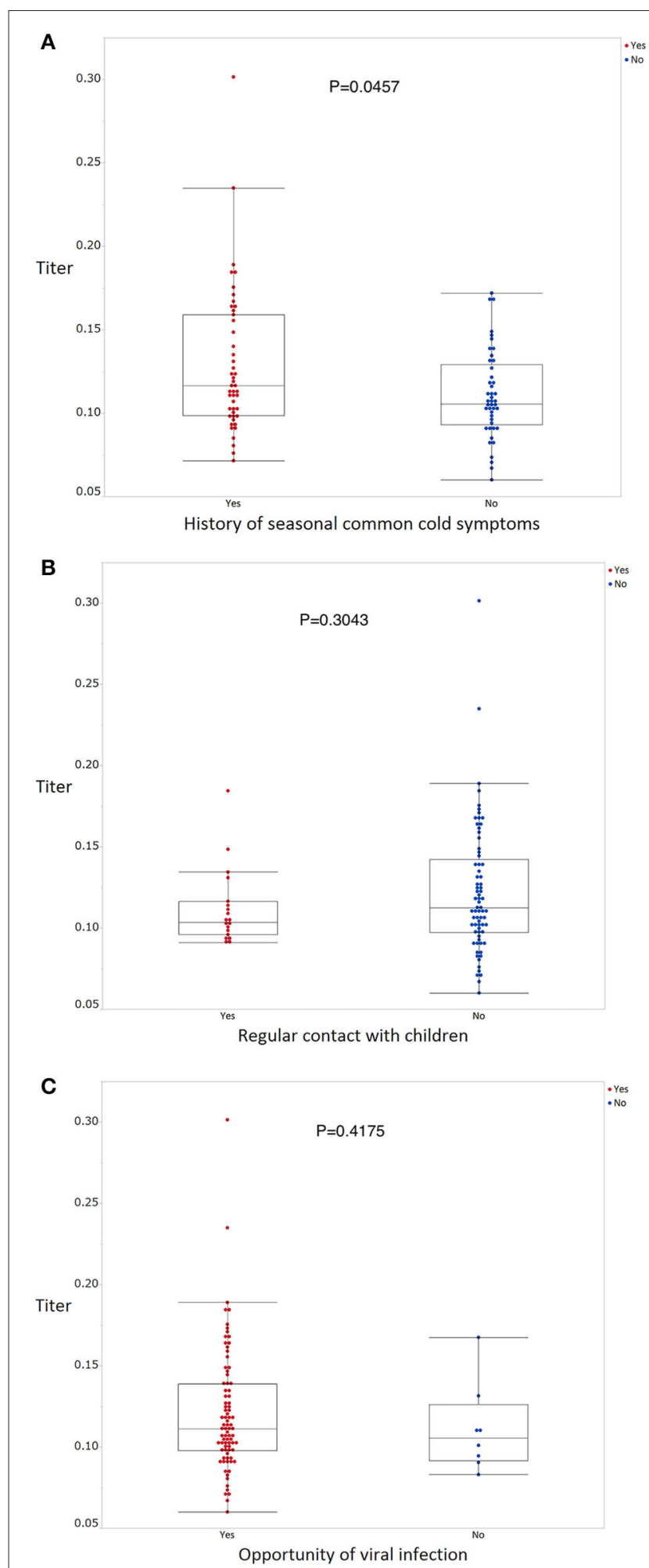

FIGURE 3 | SARS-CoV-2 IgG antibody titers stratified according to exposure status as determined using questionnaires concerning behavior patterns (A-C). Wilcoxon rank sum tests were used to compare the titer of SARS-CoV-2 IgG antibody levels between the groups, with $p$-values $<0.05$ considered statistically significant. data from government reports. Furthermore, the number of participants with borderline antibody status in our study was nearly 3 times that of participants with a positive antibody status.

Recently, several studies have reported that the populationwide seroprevalence of SARS-CoV-2 antibodies was higher than expected, based on the number of confirmed cases $(7,8)$. For example, in Kobe city, Japan, 3.3\% of outpatients tested SARSCoV-2 IgG antibody positive (8). Using quantitative methods, our results showed there were $>3$ times the number of people sensitized with SARS-CoV-2 than those found to have positive SARS-CoV-2 IgG antibody. Given that the pathogenicity of SARS-CoV-2 appears to be similar to SARS-CoV, most patients infected with SARS-CoV-2 will express specific IgG antibodies within 1 week-3 months after infection (9). In light of this timeline of seroconversion, the study participants with a positive or borderline antibody status were likely to have been exposed to SARS-CoV-2 between December 2019 and March 2020. These findings suggest that COVID-19 was already present in Kyoto at the early stages of pandemic. The period between December and March is a time of heightened tourist activity in Kyoto, in particular, involving tourists from China and Taiwan who are celebrating the Chinese New Year spring festival. After the spring festival, on March 5, 2020, the Japanese government implemented a strict ban on travelers arriving from China.

According to epidemiological data provided by the WHO (1) and by Johns Hopkins University (4), incidence and case-fatality rates in major European countries (Germany, United Kingdom, France, Italy, and Spain) and the United States are much higher than those in major Asian countries (China, Japan, South Korea, and Taiwan). There are several possible explanations for this phenomenon. Differences in lifestyle and behavioral habits between Western and Asian populations might explain some of the variability in these rates. Some studies have shown a correlation between universal BCG vaccination policy, and morbidity and mortality associated with COVID-19 (10, 11). Although this hypothesis has resulted in clinical trials to evaluate the efficacy of BCG vaccination against COVID-19 (NCT04327206 and NCT04362124), restricted basic and clinical evidence makes this association difficult to evaluate. Meanwhile, other authors have suggested that differences in viral genotypes and virulence may affect morbidity and mortality associated with COVID-19; however, this explanation requires further elaboration. The National Institute of Infectious Diseases of Japan reported that the first wave of the COVID-19 pandemic emerged from Wuhan, China, and flattened toward the end of March; however, a second wave emerged from European countries, spreading across Japan after the end of March (12). Nevertheless, even during the second wave, Japan retained its much lower morbidity and mortality rates compared to those of Western countries, as reported at the end of April 2020 (13). Kamikubo and Takahashi hypothesized that the pre-pandemic spread of a low-virulence type of SARS-CoV-2 and subsequent exposure to a mild-virulence type of SARS-CoV-2 induced herd immunity, which reduced the severity of a high-virulence type of SARS-CoV-2 in Japan (14). The findings concerning borderline antibody titers in the present study offer some support 
for this hypothesis. In this study, participants with a history of seasonal common cold from winter 2019 to early spring 2020 had a significantly higher SARS-CoV-2 antibody titer than those with no such history, which might have resulted from pre-pandemic exposure to low- and middle-virulence types of SARS-CoV-2. Importantly, a history of exposure to seasonal cold should not be interpreted as equivalent to a history of subclinical exposure to SARS-CoV-2 virus, since this virus was supposedly absent from the environment during the last season of the common cold. Further research is required to verify this hypothesis.

This study had several limitations. First, this was a singlecenter study; therefore, selection bias might have affected our findings. Second, the small sample size restricted the statistical power of our analyses. Third, as our participants were recruited from departments where exposure to COVID-19 was more likely, the reported seroprevalence might be an overestimate relative to that of workers in other departments or within the general population. Fourth, because the COVID-19 pandemic is ongoing, a significant proportion of available research results that we have referred to might be premature. Fifth, we did not evaluate the IgM antibody. A negative serum for IgG antibody might nevertheless contain a specific IgM antibody, especially as samples were obtained at the early stages of the pandemic. The interpretation of these results would likely be affected by the quantitation of IgM.

In conclusion, our study findings indicated a relatively high frequency of healthcare workers with a positive or borderline SARS-CoV-2 antibody status in the southern part of Kyoto city, an area frequented by tourists. Our results suggest that COVID-19 might already have been present in Kyoto at the early stage of the pandemic. Several previous studies have evaluated SARS-CoV-2 antibody profiles in patients with COVID-19 (15-17); however, our study is the first to quantitatively evaluate antibody levels in healthcare workers involved with patients during the COVID-19 pre-pandemic period. Serial evaluation of SARS-CoV-2 IgG antibody status is likely to reveal risk factors associated with COVID-19 susceptibility and mechanisms of disease spread. Finally, these results should be approached with caution, as there remains a lack of evidence regarding the role of antibodies present after recovery from COVID-19 in developing immunity against subsequent infections.

\section{REFERENCES}

1. World Health Organization. Coronavirus Disease (COVID-19) Situation Reports. (2020). Available online at: https://www.who.int/emergencies/ diseases/novel-coronavirus-2019/situation-reports/ (accessed October 10, 2020).

2. Guan WJ, Ni ZY, Hu Y, Liang WH, Ou CQ, He JX, et al., China Medical Treatment Expert Group for Covid-19. Clinical characteristics of coronavirus disease 2019 in China. N Engl J Med. (2020) 382:1708-20. doi: 10.1056/NEJMoa2002032

3. Chen N, Zhou M, Dong X, Qu J, Gong F, Han Y, et al. Epidemiological and clinical characteristics of 99 cases of 2019 novel coronavirus pneumonia

\section{DATA AVAILABILITY STATEMENT}

The raw data supporting the conclusions of this article will be made available by the authors, without undue reservation.

\section{ETHICS STATEMENT}

The studies involving human participants were reviewed and approved by NHO Kyoto Medical Center IRB. The patients/participants provided their written informed consent to participate in this study.

\section{AUTHOR CONTRIBUTIONS}

KF and SK designed the study and collected blood samples. KF, $\mathrm{SK}, \mathrm{OK}, \mathrm{HH}$, and TO recruited the participants and collected the data. TT, NS-A, and AY managed the ELISA tests and interpreted the results. KF, SK, and OK participated in the statistical analysis. $\mathrm{KF}$ and SK drafted and revised the manuscript. All authors contributed to the article and approved the submitted version.

\section{FUNDING}

This study was funded by the National Hospital Organization annual fiduciary funds. The National Hospital Organization fiduciary funds and a Grant-in-Aid for Young Scientists (B), KAKENHI, Japan Society for the Promotion of Science, Japan (Grant Number 17K16067).

\section{ACKNOWLEDGMENTS}

The authors appreciated the contributions of Takayuki Inoue and Chinami Shiraiwa who conducted the ELISA tests. The authors thank Drs. Koji Hasegawa and Hiroshi Okuno for their advice and support in obtaining an IRB approval. The authors also thank the members of the Department of Infectious Diseases (Drs. Eriko Kashihara, Kosuke Doi, Syuhei Ikeda, Daisuke Hirai, Masayuki Hashimoto and Koichi Seta) and Emergency Medicine (Drs. Hiroyuki Tanaka, Satoru Beppu and Kei Nishiyama) for their assistance with this study and their clinical management of COVID-19.

This manuscript has been released as a pre-print at medRXiv (18).

in Wuhan, China: a descriptive study. Lancet. (2020) 395:507-13. doi: 10.1016/S0140-6736(20)30211-7

4. Johns Hopkins University and Medicine. Coronavirus Resource Center Available online at: https://coronavirus.jhu.edu/map.html (accessed October 10, 2020).

5. Qi W, Su S, Xiao C, Zhou P, Li H, Ke C, et al. Antibodies against H10N8 avian influenza virus among animal workers in Guangdong Province before November 30, 2013, when the first human H10N8 case was recognized. BMC Med. (2014) 12:205-14. doi: 10.1186/s12916-014-0205-3

6. Kyoto City Official Website. Novel Coronavirus Infection. The Trend of the Latest. Available online at: https://www.city.kyoto.lg.jp/hokenfukushi/page/ 0000268303.html (accessed November 25, 2020). 
7. Bendavid E, Mulaney B, Sood N, Shah S, Ling E, Bromley-Dulfano R, et al. COVID-19 antibody seroprevalence in Santa Clara County, California. medRXiv. (2020). doi: 10.1101/2020.04.14.20062463

8. Doi A, Iwata K, Kuroda H, Hasuike T, Nasu S, Kanda A, et al. Estimation of seroprevalence of novel coronavirus disease (COVID-19) using preserved serum at an outpatient setting in Kobe, Japan: a cross-sectional study. medRXiv. (2020). doi: 10.1101/2020.04.26.20079822

9. Lin Q, Zhu L, Ni Z, Meng H, You L. Duration of serum neutralizing antibodies for SARS-CoV-2: lessons from SARS-CoV infection. J Microbiol Immunol Infect. (2020) 53:821-2. doi: 10.1016/j.jmii.2020.03.015

10. Miller A, Reandelar MJ, Fasciglione K, Roumenova V, Li Y, Otazu GH. Correlation between universal BCG vaccination policy and reduced morbidity and mortality for COVID-19: an epidemiological study. medRXiv. (2020). doi: $10.1101 / 2020.03 .24 .20042937$

11. Akiyama Y, Ishida T. Relationship between COVID-19 death toll doubling time and national BCG vaccination policy. medRXiv. (2020). doi: 10.1101/2020.04.06.20055251

12. National Institute of Infectious Diseases of Japan. Coronavirus disease (COVID-19). (2020). Available online at: https://www.niid.go.jp/niid/en/ (accessed October 10, 2020).

13. Ministry of Health, Labour and Welfare of Japan. Coronavirus Diseases (COVID-19) Situation. (2020). Available online at: https://www.mhlw.go.jp/ stf/seisakunitsuite/bunya/newpage_00032.html (accessed October 10, 2020).

14. Kamikubo Y, Takahashi A. Paradoxical dynamics of SARS-CoV-2 by herd immunity and antibody-dependent enhancement. Cambridge Open Engage. (2020). doi: 10.33774/coe-2020-fsnb3-v2
15. Zhao J, Yuan Q, Wang H, Liu W, Liao X, Su Y, et al. Antibody responses to SARS-CoV-2 in patients of novel coronavirus disease 2019. Clin Infect Dis. (2020) 71:2027-34. doi: 10.1093/cid/ciaa344

16. Xiang F, Wang X, He X, Peng Z, Yang B, Zhang J, et al. Antibody detection and dynamic characteristics in patients with COVID-19. Clin Infect Dis. (2020).

17. Qu J, Wu C, Li X, Zhang G, Jiang Z, Li X, et al. Profile of IgG and IgM antibodies against severe acute respiratory syndrome coronavirus 2 (SARSCoV-2). Clin Infect Dis. (2020). doi: 10.1093/cid/ciaa489

18. Fujita K, Kada S, Kanai O, Hata H, Odagaki T, Satoh-Asahara N, et al. Quantitative SARS-CoV-2 antibody screening of healthcare workers in the southern part of Kyoto city during the COVID-19 peri-pandemic period. medRXiv. (2020). doi: 10.1101/2020.05.12.20 098962

Conflict of Interest: The authors declare that the research was conducted in the absence of any commercial or financial relationships that could be construed as a potential conflict of interest.

Copyright (อ 2020 Fujita, Kada, Kanai, Hata, Odagaki, Satoh-Asahara, Tagami and Yasoda. This is an open-access article distributed under the terms of the Creative Commons Attribution License (CC BY). The use, distribution or reproduction in other forums is permitted, provided the original author(s) and the copyright owner(s) are credited and that the original publication in this journal is cited, in accordance with accepted academic practice. No use, distribution or reproduction is permitted which does not comply with these terms. 